\author{
Abstracta Iranica \\ Abstracta Iranica Revue bibliographique pour le domaine irano-aryen \\ Volume 32-33 | 2013 \\ Comptes rendus des publications de 2009-2010
}

\title{
Fereshteh Davaran. Continuity in Iranian Identity: Resilience of a Cultural Heritage
}

Ève Feuillebois-Piérunek

\section{OpenEdition}

1 Journals

\section{Édition électronique}

URL : http://journals.openedition.org/abstractairanica/40909

DOI : 10.4000/abstractairanica.40909

ISSN : 1961-960X

Éditeur :

CNRS (UMR 7528 Mondes iraniens et indiens), Éditions de l'IFRI

\section{Édition imprimée}

Date de publication : 1 décembre 2013

ISSN : 0240-8910

\section{Référence électronique}

Ėve Feuillebois-Piérunek, «Fereshteh Davaran. Continuity in Iranian Identity: Resilience of a Cultural Heritage », Abstracta Iranica [En ligne], Volume 32-33 | 2013, document 409, mis en ligne le 01 juillet 2016, consulté le 26 septembre 2020. URL : http://journals.openedition.org/abstractairanica/40909 DOI : https://doi.org/10.4000/abstractairanica.40909

Ce document a été généré automatiquement le 26 septembre 2020.

Tous droits réservés 


\title{
Fereshteh Davaran. Continuity in Iranian Identity: Resilience of a Cultural Heritage
}

\author{
Ève Feuillebois-Piérunek
}

\section{RÉFÉRENCE}

Fereshteh Davaran. Continuity in Iranian Identity: Resilience of a Cultural Heritage. London/ New York, Routledge, 2010, $288 \mathrm{p}$.

1 S'appuyant sur une étude de l'histoire, des religions et de la littérature, l'A. cherche à définir une identité culturelle iranienne et de montrer les liens entre le passé antéislamique de l'Iran et son histoire à partir de la conquête arabe jusqu'à la période contemporaine. Pour se faire, elle examine et compare la littérature de conseil préislamique (andarz) et l'étiquette musulmane (adab), montrant l'influence que la première a exercée sur la seconde.

Elle part du constat que les Iraniens ont été traités de manière quelque peu injuste dans l'historiographie islamique et occidentale, leur contribution étant minimisée ou déniée. Il existe plusieurs raisons à cela : la nature des sources pour la plupart étrangères (élamites, assyriennes, égyptiennes, grecques, romaines, chinoises, arabes, turques, juives, occidentales,...), la dilution de la voix iranienne dans le concert musulman au début de la période islamique avec la rédaction par des Iraniens d'œuvres en arabe, et l'hégémonie de l'Occident dans la recherche historique à l'époque moderne avec les déformations et les partis-pris inévitables. Pour remédier à cette situation, elle propose de donner une lecture iranienne des sources historiques et littéraires.

3 Le premier chapitre résume l'histoire de l'Iran des premières informations disponibles à la conquête d'Alexandre. Elle examine les sources disponibles: vestiges archéologiques, épigraphie achéménide, textes grecs et romains. Elle remarque que les sources purement iraniennes sont de caractère politique et bureaucratique et ne 
permettent pas de se faire une idée de la culture et de l'histoire, que beaucoup de textes iraniens importants ont été transmis oralement, que les sources étrangères donnent une version des faits biaisée. Elle démontre que les proclamations de Darius I anticipent les textes moraux d'andarz.

4 Le deuxième chapitre retrace la période allant de la chute des Achéménides à la fin de l'empire sassanide à travers l'étude des textes, de la numismatique et de l'archéologie, une attention particulière étant accordée aux Parthes généralement très négligés par l'historiographie. F. Davaran s'efforce de montrer la continuité politique, sociale et artistique de cette longue période allant de -330 à 630 .

Le troisième chapitre aborde la question de la religion préislamique à travers l'étude des mouvements de population et du panthéon. Il conclut à une continuité culturelle au sein du zoroastrisme qui se trouverait dans le prolongement du passé religieux des anciens Iraniens, et à un éloignement de cette continuité pour le manichéisme et le mazdakisme.

6 Le quatrième chapitre analyse la littérature moyen-perse, et en particulier son genre le plus important, la littérature de conseil (andarz), élaborée à partir d'une tradition orale. Ce courant littéraire dépasse l'aspect religieux et rituel en dispensant des conseils pratiques pour la vie de tous les jours. L'A. en analyse les thèmes centraux.

7 Le cinquième chapitre passe en revue les implications culturelles de la conquête islamique de l'Iran : perte de la religion et adoption progressive de l'islam, utilisation de la langue arabe dans la culture écrite, revendication de l'héritage préislamique et revivification de la culture et de la langue iraniennes, traduction de textes moyenperses en arabe, développement d'une littérature persane métissant les cultures arabe et iranienne, rôle important joué par les Iraniens dans le développement de la civilisation arabo-musulmane et dans la vie intellectuelle, politique et administrative.

8 Le sixième chapitre s'appuie sur les acquis des chapitres précédents pour brosser un portrait des débuts de la littérature persane islamique, et en particulier le genre de l' $a d a b$, montrant que celui-ci relève d'une identité duelle, iranienne et islamique.

\section{AUTEURS}

\section{ÈVE FEUILLEBOIS-PIÉRUNEK}

Université Sorbonne Nouvelle-Paris 3, Mondes iranien et indien, Paris 